Revista Brasileira de Agricultura Irrigada v.10, nº.6, p. 1056 - 1064, 2016

ISSN 1982-7679 (On-line)

Fortaleza, CE, INOVAGRI - http://www.inovagri.org.br

DOI: $10.7127 /$ rbai.v10n600506

Protocolo 506.16 - 08/11/2016 Aprovado em 10/12/2016

\title{
PRODUÇÃO DE GENÓTIPOS DE TOMATE TIPO SALADA EM DUAS ÉPOCAS DE PLANTIO
}

\author{
Jony Eishi Yuri ${ }^{1}$; Nivaldo Duarte Costa ${ }^{2}$; Geraldo Milanez de Resende${ }^{1}$; Tainá Dourado \\ Ferreira $^{3}$; Miriam Clebia Silva ${ }^{3}$
}

\begin{abstract}
RESUMO
Realizou-se o presente trabalho objetivando avaliar o comportamento produtivo de genótipos de tomate do tipo salada, com hábito de crescimento determinado, em duas épocas do ano, nas condições do Submédio do Vale do São Francisco. O experimento foi conduzido no Campo em Petrolina-PE, utilizando o delineamento blocos ao acaso no esquema de parcelas subdivididas, com três repetições. Nas parcelas ficaram as épocas de plantio (entre agosto e dezembro de 2012 e entre março e julho de 2013) e na subparcela os genótipos (LAM 327 (Embrapa); LAM 336 (Embrapa); LAM 337 (Embrapa); LAM 338 (Embrapa); LAM 341 (Embrapa); PI922863 (IPA); Itapuã (Eagle); Nanda (Agristar) e Colono (Sakata). Em termos de produtividade total e comercial, independentemente do genótipo, o cultivo de segundo semestre foi sempre superior, com médias de 75,9 e 62,9 t ha ${ }^{-1}$. Quanto à produtividade comercial de frutos, no cultivo de primeiro semestre, as cvs. Itapuã (40,6 t ha $\left.{ }^{-1}\right)$ e Nanda $(36,4$ $\mathrm{t} \mathrm{ha}^{-1}$ ) foram superiores às demais. Nas condições de segundo semestre, as cvs. Itapuã (85,5 t $\left.h^{-1}\right)$, Colono (75,6 t ha $\left.{ }^{-1}\right)$ e Nanda $\left(72,3 t h^{-1}\right)$ foram os materiais que se destacaram. Maiores massas frescas de frutos foram obtidas no cultivo de segundo semestre. A exceção dos genótipos LAM 336, LAM 337 e LAM 338, os demais apresentaram similaridade em termos de massa fresca de fruto, não apresentando diferenças estatísticas nas duas épocas de cultivo. Assim, conclui-se que é viável o cultivo de tomate do tipo salada de hábito de crescimento determinado no Submédio do Vale do São Francisco o ano todo, sendo que no cultivo de primeiro semestre as cultivares Itapuã e Nanda são as mais recomendadas, enquanto para o segundo semestre além dessas, indica-se também a cultivar Colono, por apresentarem maiores produtividades e frutos de padrão comercial adequado.
\end{abstract}

Palavras-chave: Solanum lycopersicum, rendimento, semiárido.

\section{SALAD TYPE TOMATO GENOTYPES PRODUCTION AT TWO SEASONS OF PLANTING}

\begin{abstract}
\footnotetext{
${ }^{1}$ Engenheiro-agrônomo, D.Sc. em Fitotecnia-Olericultura, pesquisador da Embrapa Semiárido, Petrolina, PE. ${ }^{2}$ Engenheiro-agrônomo, M.Sc. em Fitotecnia-Olericultura, pesquisador da Embrapa Semiárido, Petrolina, PE. ${ }^{3}$ Estagiária/Embrapa Semiárido, estudante do curso de Biologia da UPE, Petrolina, PE.
} 
To evaluate the productive performance of salad type tomato genotypes, with determined growth habit, in two seasons of the year, at the Sub medium of São Francisco river Valley this work was realized. The experiment was conducted at the Experimental Station of Bebedouro, belongs to Embrapa, in Petrolina-PE, in a factorial design with two factors: growing seasons and genotypes. The first season, from August to December 2012 and the second, from March to July 2013. Nine genotypes: LAM 327 (Embrapa); LAM 336 (Embrapa); LAM 337 (Embrapa); LAM 338 (Embrapa); LAM 341 (Embrapa); PI922863 (IPA); Itapuã (Eagle); Nanda (Agristar) and Colono (Sakata) were evaluated. The experimental design was a randomized block design, repeated three times. In terms of total and commercial yield, irrespective of genotype, the second half of cultivation was always higher, with averages of 75.9 and $62.9 \mathrm{t} \mathrm{ha}^{-1}$. As for commercial fruit production in the first half of cultivation, the cvs. Itapuã (40.6 t ha-1) and Nanda (36,4 t ha-1) were higher than the others. Under the conditions of the second half, the cvs. Itapuã (85.5 $\left.\mathrm{t} \mathrm{ha}^{-1}\right)$, Settler (75.6 t ha-1) and Nanda (72.3 $\left.\mathrm{t} \mathrm{ha}^{-1}\right)$ were the materials that stood out. Larger fruit fresh mass were obtained in the second half cultivation. The exception of genotypes LAM 336 LAM 337 and LAM 338, the others showed similarity in terms of fresh fruit mass, showing no statistical differences in the two growing seasons. Therefore, the conclusion is that it is viable to grow salad type tomatoes with determined growth habit at the Sub medium of São Francisco river Valley year-round, being that in the first semester the cultivars Itapuã and Nanda are the most recommended, while for the second semester besides these, the cultivar Colono is also indicated, because they present higher yields and fruits of adequate commercial standard.

Keywords: Solanum lycopersicum, yield, semiarid.

\section{INTRODUÇÃO}

Na região Nordeste do Brasil, o cultivo do tomateiro (Solanum lycopersicum L.) é realizado basicamente por pequenos produtores, principalmente nos Estados de Pernambuco, Bahia e Ceará, sendo uma atividade de grande importância socioeconômica. Os estados da Bahia e Pernambuco foram responsáveis em 2015, por $76,8 \%$ do total da produção nordestina, ou seja, aproximadamente 417,4 mil t ano $^{-1}$ (LSPA, 2016).

O Submédio do Vale do São Francisco, durante a década de 1980 e até meados da década seguinte, foi um importante polo de produção de tomate industrial. Após este período, por uma série de razões, entre as quais os problemas fitossanitários e de elevado custo unitário de produção, a região sofreu o declínio da agroindústria do tomate (SILVA; GIORDANO, 2000). No entanto, a atividade para o mercado in natura prosperou, mantendo o uso dos mesmos tipos de materiais indicados para processamento.

Dentre as cultivares com destino ao mercado de frutos in natura, pode-se constatar uma grande variabilidade nos valores do rendimento produtivo. De acordo com LSPA (2016), em 2015 no Nordeste brasileiro a produtividade média foi de $42,1 \mathrm{t} \mathrm{ha} \mathrm{h}^{-1}$, com cultivares de tomate do tipo determinado, enquanto que no Sudeste e Centro-Oeste esse valor sobe para 72,1 e 83,4 t ha-1, respectivamente, sendo que nestas regiões, 0 tipo de tomate é o indeterminado.

Existem diferenças que caracterizam os tomates destinados à indústria daqueles de mesa, entre as quais, o formato dos frutos, o teor de sólidos solúveis, a firmeza e, principalmente, na forma de condução da planta. Para o processamento industrial a condução se dá no sistema rasteiro, com intuito de diminuir o custo de produção, necessitando de cultivares que apresentem maturação de frutos de forma simultânea, para facilitar a colheita. No caso de tomate para mesa, a condução se dá por meio de tutoramento das plantas, utilizando-se cultivares com hábito de crescimento indeterminado, onde de tempo em tempo a planta emite novos cachos de flores e a planta pode atingir mais de $2,0 \mathrm{~m}$ de 
comprimento (FILGUEIRA, 2008).

De modo geral, as variações nas respostas produtivas estão relacionadas a diversos fatores, entre os quais, o local de cultivo, a época de produção, o manejo de cultivo adotado, cultivar explorada, forma de condução, resistência a pragas e doenças e uso ou não de ambiente protegido (CARVALHO; TESSARIOLLI NETO, 2005; GUALBERTO et al., 2007; Boiteux et al., 2012; PINHEIRO et al., 2012; QUEZADO-DUVAL et al., 2014).

Com relação à época de cultivo o tomateiro requer temperaturas superiores a 10 ${ }^{\circ} \mathrm{C}$ e inferiores a $35{ }^{\circ} \mathrm{C}$, e ainda para cada fase do desenvolvimento requer uma faixa ótima de temperatura do ar, ou seja, germinação de 16 a $29{ }^{\circ} \mathrm{C}$, período vegetativo de 20 a $24{ }^{\circ} \mathrm{C}$; floração de 18 a $24^{\circ} \mathrm{C}$; pegamento de frutos de 13 a $18{ }^{\circ} \mathrm{C}$, durante a noite, e de 19 a $25^{\circ} \mathrm{C}$, durante o dia e na maturação de 20 a $24{ }^{\circ} \mathrm{C}$, intervalo ideal para a formação do licopeno, substância responsável pela pigmentação vermelha dos frutos (GÓMEZ et al., 2000; ADAMS; VALDÉS, 2002; ALVARENGA, 2004). A temperatura ótima de crescimento para a maioria dos cultivares encontra-se entre os $15^{\circ}-25^{\circ} \mathrm{C}$, tendo como limite mínimo de sobrevivência os $10^{\circ} \mathrm{C}$ e limite máximo $38^{\circ} \mathrm{C}$ (NAIKA et al., 2006). Já Segundo Filgueira (2008), a temperatura ótima para a produção de tomate varia entre $21-28{ }^{\circ} \mathrm{C}$ durante o dia e 15 $20{ }^{\circ} \mathrm{C}$ durante a noite e, temperaturas diurnas e noturnas mais elevadas prejudicam a frutificação e fixação dos frutos. Quando a temperatura afasta-se do ótimo, ocorre estresse nas plantas, havendo menor liberação e germinação do grão de pólen, menor fixação dos frutos e ocorrência de frutos pequenos e com poucas sementes (FONTES; SILVA, 2005).

Considerando a necessidade de selecionar novas cultivares, específicas para consumo in natura e que melhor atendam as exigências do mercado, realizou-se o presente trabalho objetivando avaliar o comportamento produtivo de genótipos de tomate do tipo salada, com hábito de crescimento determinado, em duas épocas de cultivo, nas condições do Submédio do Vale do São Francisco.

\section{MATERIAL E MÉTODOS}

Um experimento foi conduzido no Campo Experimental de Bebedouro, da Embrapa Semiárido, em Petrolina-PE (latitude $9^{\circ} 8^{\prime} \quad 8,9^{\prime \prime} \mathrm{S}$, longitude $40^{\circ} 18^{\prime} 33,6^{\prime \prime} \mathrm{O}$, altitude $365,5 \mathrm{~m}$ ), em esquema fatorial com dois fatores: épocas de cultivo e genótipos. A primeira época, entre agosto e dezembro de 2012 (segundo semestre, temperaturas mais elevadas - período seco) e a segunda, entre março e julho de 2013 (primeiro semestre, temperaturas mais amenas - período chuvoso). Ao longo do experimento, formam observadas temperaturas mínimas médias de $21,4^{\circ} \mathrm{C}$ e $22,0^{\circ} \mathrm{C}$, temperaturas máximas médias de $34,0^{\circ} \mathrm{C}$ e $32,9^{\circ} \mathrm{C}$ e precipitação total de 14,5 $\mathrm{mm}$ e $63,2 \mathrm{~mm}$ na primeira época e segunda época, respectivamente. Foram avaliados nove genótipos: LAM 327 (Embrapa); LAM 336 (Embrapa); LAM 337 (Embrapa); LAM 338 (Embrapa); LAM 341 (Embrapa); PI922863 (IPA); Itapuã (Eagle); Nanda (Agristar) e Colono (Sakata). O delineamento experimental foi de blocos casualizados, repetidos três vezes. A parcela foi constituída por uma linha de sete plantas, considerando-se como parcela útil as cinco plantas centrais.

O solo da área experimental foi classificado como Argissolo Amarelo eutrófico de textura arenosa (SANTOS et al., 2006), tendo sido previamente caracterizado quanto aos aspectos químicos: $\mathrm{P}=51,43 \mathrm{mg} \mathrm{dm}^{-3} ; \mathrm{K}=$ $1,30 \mathrm{cmol}_{\mathrm{c}} \mathrm{dm}^{-3} ; \mathrm{Ca}=0,70 \mathrm{cmol}_{\mathrm{C}} \mathrm{dm}^{-3} ; \mathrm{Mg}=$ $0,40 \mathrm{cmol}_{\mathrm{C}} \mathrm{dm}^{-3} ; \mathrm{H}+\mathrm{Al}=2,24 \mathrm{cmol}_{\mathrm{c}} \mathrm{dm}^{-3}$; CTC efetiva $=4,73 \mathrm{cmol}_{\mathrm{C}} \mathrm{dm}^{-3} ; \mathrm{V} \%=52,64 ; \mathrm{pH}$ em água $(1: 2,5)=6,78 ; \mathrm{B}=0,90 \mathrm{mg} \mathrm{dm}^{-3} ; \mathrm{Cu}=$ $0,80 \mathrm{mg} \mathrm{dm}^{-3} ; \mathrm{Fe}=14,90 \mathrm{mg} \mathrm{dm}^{-3} ; \mathrm{Mn}=41,30$ $\mathrm{mg} \mathrm{dm}{ }^{-3} ; \mathrm{Zn}=3,50 \mathrm{mg} \mathrm{dm}^{-3}$.

O preparo do solo constou de uma aração, gradagem e confecção de canteiros com intuito de favorecer o desenvolvimento das plantas. Os canteiros tiveram uma base elevada de 0,10 m com 1,0 m de largura. Realizou-se a adubação de fundação, de acordo as recomendações de Cavalcante (2008). Em cada canteiro foi instalada uma linha de tubo gotejador com emissores com vazão de 1,6 L h 1 , diâmetro nominal (DN) de $16 \mathrm{~mm}$ e espaçados entre si de 0,50 m. Em seguida, 
aplicou-se um filme plástico (mulching) na cor prata sobre os canteiros com a finalidade de minimizar a ocorrência de plantas invasoras. Foram abertos orifícios de $75 \mathrm{~mm}$ a cada $0,5 \mathrm{~m}$. Assim, o espaçamento entre linhas e entre plantas foi de 2,0 m x 0,5 m, respectivamente. Esse procedimento foi similar nas duas épocas de cultivo.

As mudas foram produzidas em bandejas de polipropileno contendo 200 células e preenchidas com substrato comercial a base de fibra de coco. As mesmas foram conduzidas em casa de vegetação em bandejas de polipropileno contendo 200 células que foram preenchidas com substrato comercial por um período de 25 dias, recebendo todos os cuidados em termos fitossanitários e de irrigação. No primeiro experimento, o transplantio foi realizado no dia 08/09/2012 e no segundo, 19/04/2013.

Durante a condução da cultura, foram realizadas pulverizações com inseticidas à base de abamectin, deltamethrin e lufenuron para o controle de mosca minadora, mosca-branca e lagartas. Utilizou-se também oxicloreto de cobre para o controle de pinta preta e mancha bacteriana. As plantas daninhas que surgiram nos orifícios da cobertura plástica, próximas às mudas, foram eliminadas manualmente. A adubação de cobertura foi realizada via fertirrigação com frequência de três aplicações semanais, sempre associadas à irrigação. A lâmina de água aplicada por irrigação foi calculada de acordo com a evapotranspiração de referência (ETo), medida pela evaporação do Tanque Classe A no período entre duas irrigações (MAROUELLI et al., 2012).

A colheita dos frutos foi iniciada quando estas se apresentaram em estádio adequado de maturação, momento em que os mesmos se apresentavam com coloração entre rosada e vermelha (BRASIL, 2002). Na primeira época, a operação foi iniciada aos 69 dias após o transplantio, e se estendendo por 20 dias, sendo realizadas seis colheitas, em intervalos de quatro dias. Para a segunda época, o início foi aos 71 dias, e se estendeu por 35 dias.

Foram avaliados o número de frutos por planta, a massa fresca de frutos por planta e de frutos, além da produtividade total e comercial de frutos. Para a avaliação da produtividade total, foram colhidos todos os frutos das parcelas, pesadas em balança e, de forma indireta, recalculada para a produtividade por hectare. O mesmo procedimento foi realizado para a avaliação da produtividade comercial, ressaltando-se que para esta característica foram retirados todos os frutos que não se enquadravam como comerciais (frutos brocados e defeituosos). No caso da massa fresca de frutos por planta, o cálculo foi realizado dividindo-se a quantidade total de frutos da parcela pelo número de plantas da parcela. Quanto à massa de fruto, dividiu-se o peso total de frutos pelo número total de frutos. Os dados obtidos foram submetidos à análise de variância (teste $\mathrm{F}$ a 5\% de probabilidade). Verificado diferença significativa entre os tratamentos, as médias foram comparadas pelo teste de Scott-Knott ao nível de 5\% de probabilidade, utilizando o programa SISVAR 4.0 (FERREIRA, 2011).

\section{RESULTADOS E DISCUSSÃO}

A característica produção de frutos por plantas foi afetada significativamente pela interação entre os fatores, assim como, para época de cultivo e genótipos. Comparando-se as épocas, verificou-se que todos os genótipos apresentaram melhor resposta quando o cultivo se deu no segundo semestre. No comparativo entre os genótipos, no cultivo de primeiro semestre, "Itapuã" (3,2 kg planta $\left.{ }^{-1}\right)$ e "Nanda" (2,9 kg planta $\left.{ }^{-1}\right)$, foram estatisticamente superiores. Nas condições de segundo semestre, as cvs. Itapuã, Colono e Nanda se destacaram, sendo superiores aos demais materiais, apresentando 6,8; 6,0 e 5,8 kg planta ${ }^{-}$ 1 , respectivamente (Tabela 1 ). Os resultados obtidos no experimento são bem superiores aos apresentados por Silva et al. (2014), que em condições do município de Catolé da Rocha-PB, obtiveram o resultado de $1,9 \mathrm{~kg} \mathrm{planta}{ }^{-1}$ como melhor resultado. 
Tabela 1. Produção de frutos por planta e número de frutos por planta de tomate do tipo salada em função de genótipos e épocas de cultivo, nas condições do Submédio do Vale do São Francisco. Petrolina, 2012/2013.

\begin{tabular}{lcccc}
\hline \multirow{2}{*}{ Genótipos } & \multicolumn{2}{c}{$\begin{array}{c}\text { Produção de frutos por planta } \\
\left(\text { kg planta }^{-1}\right)\end{array}$} & \multicolumn{2}{c}{ Número de frutos por planta } \\
\cline { 2 - 5 } & \multicolumn{3}{c}{ Erimeca de cultivo/Semestre } & \\
\cline { 2 - 5 } & Segundo & $3,2 \mathrm{Ab}$ & $87,0 \mathrm{Ba}$ & $43,3 \mathrm{Ab}$ \\
\hline Itapuã & $6,8 \mathrm{Aa}$ & $3,0 \mathrm{Ab}$ & $79,4 \mathrm{Ba}$ & $40,0 \mathrm{Ab}$ \\
Nanda & $5,8 \mathrm{Aa}$ & $1,4 \mathrm{Bb}$ & $57,8 \mathrm{Ca}$ & $26,0 \mathrm{Bb}$ \\
LAM 341 & $5,0 \mathrm{Ba}$ & $1,8 \mathrm{Bb}$ & $35,9 \mathrm{Ca}$ & $18,9 \mathrm{Bb}$ \\
LAM 336 & $4,7 \mathrm{Ba}$ & $1,9 \mathrm{Bb}$ & $47,2 \mathrm{Ca}$ & $13,8 \mathrm{Bb}$ \\
LAM 337 & $5,2 \mathrm{Ba}$ & $1,8 \mathrm{Bb}$ & $70,5 \mathrm{Ba}$ & $23,8 \mathrm{Bb}$ \\
Colono & $6,1 \mathrm{Aa}$ & $2,0 \mathrm{Bb}$ & $179,5 \mathrm{Aa}$ & $73,4 \mathrm{Ab}$ \\
PI922836 & $4,4 \mathrm{Ba}$ & $2,3 \mathrm{Bb}$ & $39,8 \mathrm{Ca}$ & $20,0 \mathrm{Bb}$ \\
LAM 338 & $4,2 \mathrm{Ba}$ & $1,4 \mathrm{Bb}$ & $38,0 \mathrm{Ca}$ & $16,1 \mathrm{Bb}$ \\
LAM327 & $3,3 \mathrm{Ca}$ & $2,1 \mathrm{~b}$ & $70,6 \mathrm{a}$ & $30,6 \mathrm{~b}$ \\
\hline Média & $5,0 \mathrm{a}$ & \multicolumn{4}{c}{3,80}
\end{tabular}

Médias seguidas de mesma letra maiúscula, em cada coluna, e minúscula na linha, não diferem entre si pelo teste de ScottKnott, a 5\% de probabilidade.

Verificou-se também para o número total de frutos por planta efeito significativo da interação entre os fatores. De modo semelhante à característica anterior, nesse também o desempenho foi superior no cultivo de segundo semestre. Nas condições de primeiro semestre, foi registrada uma variação de 13,8 a 73,4 frutos planta ${ }^{-1}$, destacando-se a cultivar PI 922863, com o maior número (73,4 frutos planta $^{-1}$ ). No cultivo desta época, as cvs. que se destacaram em termos de produtividade total e comercial ("Itapuã" e "Nanda"), apresentaram, respectivamente, 43,3 e 40,0 frutos planta $^{-1}$, sendo com o genótipo PI 922863, superiores aos demais. Os valores obtidos nessa época do ano foram semelhantes aos observados por Machado Neto (2014), que avaliando cultivares de tomate em diferentes sistemas de cultivo, obteve uma média de 39,2 frutos planta $^{-1}$. Quando o cultivo foi realizado no segundo semestre, o genótipo PI 922863 foi novamente destaque (Tabela 1). Entretanto, deve-se salientar que essa maior quantidade de frutos por planta não resultou em maior produtividade, pois a massa de fruto foi a menor entre os materiais testados. Quando comparado com outros resultados, verifica-se, entre os melhores materiais avaliados nesta pesquisa, que a quantidade de frutos por planta foi similar à obtida por Santos et al. (2001).

Em relação à massa fresca média de fruto verificou-se também efeito significativo da interação entre genótipos e épocas de cultivo (Tabela 2). Entre as épocas de cultivo, com exceção dos genótipos LAM 336, LAM 337 e LAM341, os demais apresentaram similaridade em termos de massa média de fruto, não apresentando diferenças estatísticas entre as duas épocas de cultivo (Tabela 2). Observou-se para os genótipos, dentro de cada época, para o cultivo de primeiro semestre, que LAM337, apresentando massa média de 140,5 g $_{\text {fruto }}{ }^{-1}$, se destacou, sendo estatisticamente superior aos demais materiais.

Tabela 2. Massa fresca de frutos de tomate do tipo salada em função de genótipos e épocas de cultivo, nas condições do Submédio do Vale do São Francisco. Petrolina, 2012/2013.

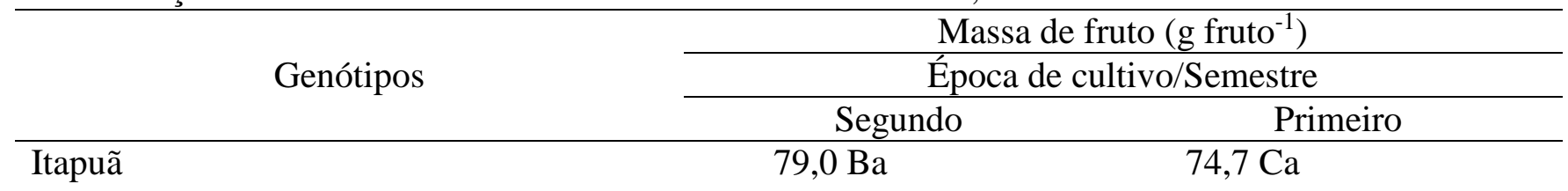




\begin{tabular}{lrr} 
Nanda & $72,6 \mathrm{Ba}$ & $62,1 \mathrm{Ca}$ \\
LAM 341 & $89,1 \mathrm{Ba}$ & $52,9 \mathrm{Cb}$ \\
LAM 336 & $132,4 \mathrm{Aa}$ & $97,4 \mathrm{Bb}$ \\
LAM 337 & $112,5 \mathrm{Ab}$ & $140,5 \mathrm{Aa}$ \\
Colono & $89,0 \mathrm{Ba}$ & $72,3 \mathrm{Ca}$ \\
PI922836 & $28,6 \mathrm{Ca}$ & $28,3 \mathrm{Da}$ \\
LAM 338 & $108,8 \mathrm{Aa}$ & $112,4 \mathrm{Ba}$ \\
LAM327 & $86,8 \mathrm{Ba}$ & $89,2 \mathrm{Ba}$ \\
\hline Média & $88,8 \mathrm{a}$ & $81,1 \mathrm{~b}$ \\
\hline C.V. (\%) & \multicolumn{2}{l}{18,96} \\
\hline \multicolumn{2}{l}{ Médias seguidas de mesma letra maiúscula, em cada coluna, e minúscula na linha, não diferem entre si pelo teste de Scott- }
\end{tabular}

$\mathrm{Na}$ sequência, separados dentro do segundo grupo ficaram os genótipos LAM 338, LAM 336 e LAM 327, com massas médias de 112,4; 97,4 e 89,2 $\mathrm{g}$ fruto $^{-1}$, respectivamente. No cultivo de segundo semestre, observou-se uma variação de 28,6 a 132,4 g $_{\text {fruto }}{ }^{-1}$, sendo os genótipos LAM 336, LAM 337 e LAM 338, novamente, os destaques (Tabela 2).

Para as duas épocas de cultivo, o pior desempenho foi apresentado pelo genótipo PI 922863, apresentando massa média de 28,3 g fruto $^{-1}$ no cultivo de primeiro semestre e 28,6 g fruto $^{-1}$ no cultivo de segundo semestre, sendo, portanto, de pouco valor comercial. Os genótipos LAM 336, LAM 337 e LAM 338 que apresentaram maiores massas médias de fruto foram as que produziram as menores quantidades de frutos por planta, consequentemente, menores produtividades.

A análise de variância da característica produtividade total evidenciou efeito significativo de modo independente para os fatores épocas de cultivo e genótipos, assim como para a interação destes. Pelos resultados do desdobramento da interação, observa-se que independentemente do genótipo, o cultivo de segundo semestre foi sempre superior. Dentre os genótipos, no cultivo de primeiro semestre, "Itapuã" e "Nanda" foram estatisticamente superiores aos demais, com produtividade total de 41,6 e 37,3 t ha-1 respectivamente (Tabela 3).

Tabela 3. Produtividade total e comercial de tomate do tipo salada em função de genótipos e épocas de cultivo, nas condições do Submédio do Vale do São Francisco. Petrolina, 2012/2013.

\begin{tabular}{lcccc}
\hline \multirow{2}{*}{ Genótipo } & \multicolumn{3}{c}{ Produtividade total $\left(\mathrm{t} \mathrm{ha}^{-1}\right)$} & \multicolumn{3}{c}{ Produtividade comercial $\left(\mathrm{t} \mathrm{ha}^{-1}\right)$} \\
\cline { 2 - 5 } & \multicolumn{4}{c}{ Época de cultivo/Semestre } \\
\cline { 2 - 5 } & Segundo & Primeiro & Segundo & Primeiro \\
\hline Itapuã & $93,4 \mathrm{Aa}$ & $41,6 \mathrm{Ab}$ & $85,5 \mathrm{Aa}$ & $40,6 \mathrm{Ab}$ \\
Nanda & $90,7 \mathrm{Aa}$ & $37,3 \mathrm{Ab}$ & $72,3 \mathrm{Aa}$ & $36,4 \mathrm{Ab}$ \\
LAM 341 & $78,1 \mathrm{Ba}$ & $18,3 \mathrm{Bb}$ & $62,3 \mathrm{Ba}$ & $17,6 \mathrm{Bb}$ \\
LAM 336 & $78,0 \mathrm{Ba}$ & $24,0 \mathrm{Bb}$ & $58,3 \mathrm{Ba}$ & $23,0 \mathrm{Bb}$ \\
LAM 337 & $77,4 \mathrm{Ba}$ & $23,7 \mathrm{Bb}$ & $64,5 \mathrm{Ba}$ & $23,7 \mathrm{Bb}$ \\
Colono & $76,8 \mathrm{Ba}$ & $22,6 \mathrm{Bb}$ & $75,6 \mathrm{Aa}$ & $22,1 \mathrm{Bb}$ \\
PI922836 & $68,1 \mathrm{Ca}$ & $25,9 \mathrm{Bb}$ & $54,7 \mathrm{Ba}$ & $25,2 \mathrm{Bb}$ \\
LAM 338 & $62,2 \mathrm{Ca}$ & $29,6 \mathrm{Bb}$ & $52,4 \mathrm{Ba}$ & $28,5 \mathrm{Bb}$ \\
LAM327 & $58,1 \mathrm{Ca}$ & $19,5 \mathrm{Bb}$ & $41,0 \mathrm{Ca}$ & $18,1 \mathrm{Bb}$ \\
\hline Média & $75,9 \mathrm{a}$ & $26,3 \mathrm{~b}$ & $62,9 \mathrm{a}$ & $25,6 \mathrm{~b}$ \\
\hline C.V. $(\%)$ & \multicolumn{5}{c}{}
\end{tabular}

Médias seguidas de mesma letra maiúscula, em cada coluna, e minúscula na linha, não diferem entre si pelo teste de ScottKnott, a 5\% de probabilidade.

No segundo semestre, as cultivares Itapuã $\left(93,4 \mathrm{t} \mathrm{ha}^{-1}\right)$ e Nanda $\left(90,7 \mathrm{t} \mathrm{ha}{ }^{-1}\right)$ foram destaque novamente, sendo estatisticamente superiores aos demais na produtividade total. 
Esses resultados estão próximos aos obtidos por Heine et al. (2015), que em condições do município de Ibicoara-BA, testando diferentes espaçamentos, na mesma época de cultivo, obtiveram produtividade total máxima de 100,2 $\mathrm{t} \mathrm{ha}^{-1}$. Verifica-se pelos resultados, uma variação expressiva na produtividade no comparativo entre as épocas de cultivo, comprovando a influência do clima no cultivo do tomateiro. De acordo com Santos (2010), altas temperaturas induzem uma série de distúrbios morfológicos e/ou fisiológicos em estruturas florais do tomateiro, resultando em menor produtividade devido a maiores taxas de abortamento e má formação de frutos. Essas informações são corroborados por Neves et al. (2013), que em trabalho de levantamento de épocas adequadas para o cultivo de tomate em diferentes localidades do Estado de Mato Grosso, verificaram restrições climáticas para o cultivo de tomate em razão de temperaturas elevadas nos meses de primavera e verão.

Quanto à produtividade comercial de frutos, houve significância para a interação entre os fatores, assim como, para época de cultivo e genótipos. No comparativo entre épocas de cultivo, observa-se que todos apresentaram melhor desempenho quando o cultivo foi realizado no segundo semestre.

Entretanto, vale salientar que as cultivares Itapuã e Nanda apresentaram maior estabilidade, proporcionando maiores produtividades, independentemente da época de cultivo, ao passo que a cv. Colono teve melhor desempenho apenas no cultivo de segundo semestre. No cultivo de primeiro semestre, as cultivares Itapuã e Nanda, com produtividades de 40,6 e 36,4 t ha $^{-1}$, respectivamente, foram superiores às demais.

Nas condições de segundo semestre, as cvs. Itapuã, Colono e Nanda, com produtividades de 85,5; 75,6 e 72,3 t ha-1, respectivamente, foram os materiais que se destacaram, sendo superiores estatisticamente aos demais (Tabela 3). Em relação à produtividade comercial obtida no cultivo de segundo semestre pelas melhores cultivares, verifica-se que são similares ou superiores aos obtidos nas regiões Sudeste e Centro-Oeste, que apresentam produtividades médias de 72,1 e 83,4 t ha ${ }^{-1}$, respectivamente (LSPA, 2016). Avaliando cultivares de crescimento indeterminado e tutoradas, Matos et al. (2012) obtiveram produtividades comerciais pouco superiores entre 95,6 e 100,8 $\mathrm{t} \mathrm{ha}^{-1}$.

\section{CONCLUSÕES}

É viável o cultivo de tomate do tipo salada de hábito de crescimento determinado no Submédio do Vale do São Francisco o ano todo, com melhores produtividades no primeiro semestre comparativamente ao segundo semestre.

No cultivo de primeiro semestre as cultivares Itapuã e Nanda são as mais recomendadas, enquanto para o segundo semestre além dessas, indica-se também a cultivar Colono, por apresentarem maiores produtividades e frutos de padrão comercial adequado.

\section{REFERÊNCIAS}

ADAMS, S.R.; VALDÉS, V.M. The effect of periods of high temperature and manipulating fruit load on the pattern of tomato yields. Journal Horticultural Science Biotechnology, v. 77, n.4, p.461-466, 2002.

ALVARENGA, M.A.R. Tomate: produção em campo, em casa de vegetação e em hidroponia. Lavras: Editora UFLA. 2004. 400p.

BOITEUX, L.S.; FONSECA, M.E.N.; VIEIRA, J.V.; PEREIRA-CARVALHO, R.C. Breeding for resistance to viral diseases. In: FRITSCHE-NETO, R.; BORÉM, A. (Org.). Plant Breeding for Biotic Stress Resistance. 1ed . Berlin: Springer -Verlag, v.1, 2012. p. 5779.

BRASIL. Ministério da Agricultura, Pecuária e Abastecimento. Portaria SARC $\mathrm{n}^{0}$ 085, de 06 de março de 2002. Regulamento técnico de identidade e qualidade para classificação do tomate. Diário Oficial da República Federativa do Brasil. Brasília, 2002. 
CARVALHO, L.A.; TESSARIOLI NETO, J. Produtividade de tomate em ambiente protegido, em função do espaçamento e número de ramos por planta. Horticultura Brasileira, v.23, n.4, p.986-989, 2005.

\section{CAVALCANTE, \\ F.J.A. \\ (Coord.).}

Recomendações de adubação para o estado de Pernambuco: $2^{\mathrm{a}}$ aproximação. Recife: IPA, 2008. 212p.

FERREIRA, D. F. Sisvar: a computer statistic alanalysis system. Ciência e Agrotecnologia, v.35, n.6, p.1039-1042, 2011.

FILGUEIRA, F.A.R. Novo Manual de Olericultura: Agrotecnologia moderna na produção e comercialização de hortaliças. Viçosa: Editora UFV, 2008. 421p.

FONTES, P.C.R.; SILVA, D.J.H. Cultura do tomate. In: FONTES PCR. (Ed.). Olericultura: teoria e pratica. Viçosa: Editora UFV, 2005. p. 457-475.

GÓMEZ, O.; CASANOVA, A.; LATERROT, H.; ANAIS, G. Mejora genética y manejo del cultivo de tomate para la producción en el Caribe. La Habana: Instituto de Ivestigaciones Horticolas "Liliana Dimitrova", 2000. 159p.

GUALBERTO, R.; OLIVEIRA， O.S.R.; GUIMARÃES, A.M. Desempenho de cultivares de tomateiro para mesa em ambiente protegido. Horticultura Brasileira, v.25, n.2, p.244-246, 2007.

HEINE, A. J. M.; MORAES, M. O. B.; PORTO, J. S.; SOUZA, J. R.; REBOUÇAS, T. N. H.; SANTOS, B. S. R. Número de hastes e espaçamento na produção e qualidade do tomate. Scinetia Plena, v.11, n.9, p.1-7, 2015. Disponível em: $<$ https://www.scientiaplena.org.br/sp/article/vie w/090202>. Acesso em: 04 jan. 2017.

Levantamento Sistemático da Produção Agrícola - LSPA. Pesquisa mensal de previsão e acompanhamento das safras agrícolas no ano civil. Instituto Brasileiro de
Geografia e Estatística - IBGE. Rio de Janeiro, v.29, n.9, p.1-79. 2016.

MACHADO NETO, A. S. Viabilidade agroeconômica da produção de tomate de 'mesa' sob diferentes sistemas de cultivo e manejo de adubação. 107f. 2014. Tese (Doutorado em Produção Vegetal). Universidade Estadual do Norte Fluminense Darcy Ribeiro. Campo de Goytacazes.

MAROUELLI, W.A.; SILVA, H.R.; SILVA, W.L.C. Irrigação do tomateiro para processamento. Brasília: Embrapa Hortaliças, 2012. 22p. (Circular Técnica 102).

MATOS, E.S.; SHIRAHIGE, F.H.; MELO, P.C.T. Desempenho de híbridos de tomate de crescimento indeterminado em função de sistemas de condução de plantas. Horticultura Brasileira, v.30, n.2, p.240-245, 2012.

NAIKA, S., DE JEUDE, J.V.L., DE GOFFAU, M., HILMI, M.; VAN DAM, B. 2006. A cultura do tomate - Produção, processamento e comercialização. Wageningen: Fundação Agromisa CTA. 2006. 104p.

NEVES, S.M.A.S.; SEABRA JUNIOR, S.; ARAÚJO, K.L.; SOARES NETO, E.R.; NEVES, R.J.; DALLACORT, R.; KREITLOW, J.P. Análise climática aplicada à cultura do tomate na região Sudoeste de Mato Grosso: subsídios ao desenvolvimento da agricultura familiar regional. Ateliê Geográfico, v.7, n.2, p.97-115, 2013.

PINHEIRO, J.B.; PEREIRA, R.B. Nematoides. In: CLEMENTE, F.M.V.T.; BOITEUX, L.S. (Org.). Produção de Tomate para Processamento Industrial. $1^{\mathrm{a}}$ ed. Brasília: Embrapa, 2012. p. 243-262.

QUEZADO-DUVAL，A.M.; NASCIMENTO, A.R.; PONTES, N.C.; MOITA, A.W.; ASSUNÇÃO, A.; GOLYNSKI, A.; INOUENAGATA, A.K.; OLIVEIRA, R.T.; CASTRO, Y.O.; MELO, B.J. Desempenho de híbridos de tomate para processamento industrial em 
pressão de begomovirose e de manchabacteriana. Horticultura Brasileira, v.32, n.4, p.446-452, 2014.

SANTOS, L.S. Murcha bacteriana, tolerância à altas temperaturas e pegamento de frutos em tomateiro. Recife: UFRPE. 2010. 16p. (Monografia).

SANTOS, H.G.; JACOMINE, P.K.T.; ANJOS, L.H.C.; OLIVEIRA, V.A.; OLIVEIRA, J.B.; COELHO, M.R.; LUMBRERAS, J.F.; CUNHA, T.J.F. (Ed.). Sistema brasileiro de classificação de solos. 2. ed. Rio de Janeiro: Embrapa Solos. 2006. 306p.

SANTOS, P.R.Z.; PEREIRA, A.S.; FREIRE, C.J.S. Cultivar e adubação NPK na produção de tomate salada. Horticultura Brasileira, v.19, n.1, p.35-39, 2001.

SILVA, J. A. M.; DUTRA, A. F.; CAVALCANTI, N. M. S.; MELO, A. S.; SILVA, F. G.; SILVA, J. M. Aspectos agronômicos do tomateiro "Caline IPA 6" cultivado sob regimes hídricos em área do semiárido. Revista Agroambiental On-Line, v.8, n.3, p.336-344, 2014. Disponível em: $<$ http://revista.ufrr.br/agroambiente/article/view /1951>. Acesso em: 04 jan. 2017.

SILVA, J.B.C.; GIORDANO, L.B. Produção mundial e nacional. In. SILVA, J.B.C.; GIORDANO, L.B. (org.). Tomate para processamento industrial. Brasília: EMBRAPA, $2000 . \quad$ p.8-11. 